\title{
ACERCA DEL CONCEPTO DE EMPRESA EN EL COODIGO DEL TRABAJO
}

\author{
PATRICIO EDUARDO YÁÑEZ MONJE* \\ Universidad de Chile
}

El Código del Trabajo define empresa como "toda organización de medios personales, materiales e inmateriales, ordenados bajo una dirección, para el logro de fines económicos, sociales, culturales o benéficos, dotada de una individualidad legal determinada". Es bien sabido que este concepto ha generado cierto debate dogmático, pues la explícita referencia a una individualidad legal determinada puede afectar la prevalencia de los derechos laborales, sobre todo los de índole colectivo (sindicalización), si se acepta que ante el desmembramiento jurídico de una organización dotada en todo caso de una dirección común, puedan constituir varias empresas para los efectos laborales, siendo cada una de ellas centro de imputación normativa respecto de los trabajadores que, si bien formalmente vinculados solo a una de ellas, materialmente son dependientes del conjunto de unidades jurídicas.

Con la dictación de Ley $N^{\circ} 20.123$, sobre subcontratación, se pretendió instalar en la discusión política (sede natural, a mi juicio, de la discusión sobre el concepto de empresa), la necesidad de la derogación de la individualidad legal determinada. No obstante, se recurrió al Tribunal Constitucional (sea porque no se debatió debidamente y se esperó la intromisión del Tribunal, o si se debatió debidamente, aquellos que no estaban de acuerdo con la derogación perdieron la discusión) para que realizara un examen tanto de fondo como de forma de la ley sobre subcontratación. Como ha sido costumbre del Tribunal de un tiempo a esta parte, no se pronunció sobre la constitucionalidad de fondo de la derogación de la individualidad legal determinada del concepto de empresa (para efectos de la ley de subcontratación), sino señaló que dicha norma era inconstitucional, pues tenía consecuencias en materia de seguridad social (deber de información de pago de obligaciones de carácter laboral y previsional), siendo dicha materia de ley de iniciativa exclusiva del Presidente de la República, en circunstancias que la ley de subcontratación se había iniciado por moción parlamentaria 1 .

\footnotetext{
* Egresado de Derecho. Universidad de Chile. Ayudante de Derecho del Trabajo en la misma universidad. Consultor Laboral LegalPublishing.

${ }^{1}$ Sentencia Tribunal Constitucional, 21 de agosto de 2006; "OCTAVO: Que la aplicación del concepto de empresa que formula el artículol 83 ter en análisis a las distintas situaciones de subcontratación contenidas en el proyecto de ley, determina los sujetos obligados al pago de cotizaciones previsionales de los trabajadores como, asimismo, la clase de responsabilidad civil de la persona denominada mandante o empresa principal en la subcontratación, responsabilidad que, por regla general, es solidaria, pero que puede convertirse en subsidiaria;

NOVENO. Que por consiguiente, estamos ante disposiciones que modifican norma sobre seguridad social o que inciden. en ella tanto del sector público como del sector privado, las cuales, conforme a lo dispuesto en el artículo 65 , inciso cuarto, $N^{\circ} 6$, de la Constitución Política, son de iniciativa exclusiva del Presidente de la República;

DÉCIMO: Que, sin embargo, y como consta del Acta de la Sesión No 67, de 10 de enero de 2006, de la Cámara de Diputados, y de los demás antecedentes que obran en conocimiento de esta magistratura, la proposición que tuvo por objeto conceptualizar la definición de empresa que se encuentra contenida en el artículo 183, surgió por indicación parlamentaria y no de la Presidenta de la República, a pesar de que se trata de una materia reservada por la Constitución a la iniciativa exclusiva del Jefe de Estado, como se ha señalado en el considerando anterior".
} 
Mucho se comentó sobre la omisión del Tribunal Constitucional sobre la materia de fondo, tanto de aquellos que piensan que existían buenas razones para sostener su inconstitucionalidad ${ }^{2}$, como de aquellos que celebraban dicha omisión, pues eso permitiría no dejar el debate cerrado ${ }^{3}$.

Con el fallido intento de modificar el concepto de empresa al menos respecto de la subcontratación laboral (sin perjuicio de su innecesariedad en esa área del derecho del trabajo, como lo sostiene algún autor ${ }^{4}$ ), el debate acerca del correcto sentido y alcance del artículo $3^{\circ}$ inciso 3 del Código del Trabajo sigue pendiente. La jurisprudencia de la Excelentísima Corte Suprema ha obviado en muchas de sus sentencias la individualidad legal determinada, trasladando el centro de imputación normativa a una pluralidad de entes jurídicos, mientras se den ciertas condiciones. La sentencia de la Corte Suprema de 11 de noviembre de 2009, hace ciertas precisiones sobre esas condiciones, necesarias para privilegiar el dato de la dirección común por sobre la unidad jurídica:

"Sexto: Que a partir de la exégesis reseñada, en varias ocasiones, esta Corte ha calificado y tratado como un único empleador a empresas cuya existencia legal, giros comerciales y vínculos dan cuenta de la concurrencia de los dos presupuestos contemplados por el legislador en el concepto amplio de empresa que establece, a saber, la coordinación hacia la consecución de ciertos objetivos comunes y la concurrencia de una individualidad legal. Se ha considerado, para estos efectos, que todas las demandadas han ejercido la misma actividad, mantienen giros estrechamente relacionados o complementarios, funcionan en un mismo lugar y bajo una sola administración, por cuanto dichos hechos dan cuenta, caso a caso, de la efectividad de haberse prestado servicios por el trabajador a un grupo económico, a una unidad jurídica, comercial, patrimonial o empresarial. De esta forma, el principio inmerso en la norma de que se trata, no puede ser soslayado con la sola división de una empresa en tantas partes como etapas tenga el proceso productivo que desarrolla o el servicio que ofrece, como ocurriría por ejemplo con la entidad que procesa o adquiere la materia prima, la que manufactura el producto, la que lo distribuye y la que lo vende.

Séptimo: Que, por cierto, con el mismo fundamento, deben sustraerse de la regulación en estudio las situaciones en que las empresas respectivas revisten identidades jurídicas propias, sin elemento alguno en común o manifiestan una independencia fáctica que las distingue entre sí.

Octavo: Que según se ha asentado en la sentencia en estudio, las demandadas de autos, si bien presentan elementos de vinculación muy marcados tanto en lo que dice relación a su propiedad como a quien ejerce el control y su representación, estos no resultan suficientes, como para que puedan ser calificadas como una sola

\footnotetext{
${ }^{2}$ Ver por ejemplo, Palavecino, Claudio, "El Concepto de Empresa y su Problemática", en: Revista Laboral Chilena, No 168 , Santiago, julio 2008.

${ }^{3}$ Ver por ejemplo UGARTE CATALDO, José Luis, "El concepto de empresa en el proyecto de subcontratación, una buena idea en el lugar equivocado", en: Revista Laboral Chilena, No 153, enero 2007.

${ }^{4}$ Ibid. p. 90
} 
empresa, desde que no se ha establecido que desarrollen un mismo giro, que sus actividades se hayan coordinado para el logro de objetivos comunes $y$, en fin, que constituyan una sola identidad jurídica”.

Se ha fundamentado en muchas ocasiones este tipo de razonamientos en el principio de la primacía de la realidad 5 , que privilegia lo que sucede en los hechos por sobre lo que está escrito en los documentos y acuerdos. Sin embargo, cabe tener cuidado en la aplicación de los principios, pues en esos casos existe una delgada línea entre juzgar de acuerdo a derecho o configurarse como un activista político. Nuestro Código Civil establece una regla de precedencia entre los distintos elementos de interpretación, y los principios generales del derecho figuran en último lugar (artículo 24 del Código Civil), y quienes se han ocupado del problema de los principios sitúan su más importante aplicación cuando las limitaciones impuestas por el propio lenguaje no dejan entrever la verdadera respuesta otorgada por la ley ${ }^{6}$ (no la respuesta correcta desde el punto de vista de ético, sino simplemente la respuesta otorgada por la ley).

La sentencia citada del máximo tribunal establece varios requisitos para que una pluralidad de entes jurídicos puedan ser considerados una sola empresa para efectos laborales, entre ellos, que posean giros estrechamente vinculados o complementarios, que rengan una sola administración, funcionen en un mismo lugar y que el trabajador preste servicios, indistintamente, a ese grupo económico. De esta manera, la jurisprudencia salva el problema relativo a la prevalencia de los derechos laborales por sobre las formas jurídicas, dejando de lado la expresión a una individualidad legal determinada.

La omisión a una individualidad legal determinada puede generar -según los parlamentarios recurrentes de inconstitucionalidad- un serio perjuicio a la libertad económica, libertad de contratación, libertad de trabajo y derecho de propiedad a las empresas presuntamente relacionadas, pues algunas empresas se pueden ver obligadas a asumir responsabilidades respecto de trabajadores en virtud de actos jurídicos de los cuales nunca formaron parte $^{7}$. Sin embargo, por otro lado, se considera un imperativo ético salvaguardar los derechos de los trabajadores, y mantenerlos a salvo del desmembramiento jurídico. Existía el temor de que el Tribunal Constitucional cerrara el debate, o más aún, que lo declarara constitucional en la ley de subcontratación, lo que reafirmaría la idea de que la individualidad legal determinada se mantuviera vigente en el concepto de empresa en la legislación laboral en general (como argumento a contrario sensu) ${ }^{8}$. Sin embargo, llama la atención

\footnotetext{
${ }^{5}$ Corte Suprema, Rol No 3631-2006, septiembre de 2006; "Carlos Mellado Backarzick con Sociedad Administradora de Servicios de Vigilancia Unimarc S.A."; “...que constiruye un derecho del hombre organizarse para producir y que tal derecho emana de su naturaleza. La ley solo tiene que reconocerlo y ampararlo. Tal facultad del ser humano ha ido variando en cuanto a su forma de ejercicio y ha ido adoptando evolucionados y diferentes modelos. Uno de ellos es el denominado "Holding o conjunto de empresas relacionadas, las que en general presentan un patrimonio común o compartido. Atento a tales cambios, en la especie ha de hacerse primar el principio de la realidad, esto es, la verdad o autenticidad en las relaciones laborales, aquello que son y no lo que las partes han querido que sean. Es la supremacía de este principio la que se ha impuesto en la resolución de los Jueces del grado y este Tribunal de Casación no puede sino considerarlo acertado" (Corte Suprema, rol No 4005-2002, 19 de julio de 2001).

${ }^{6}$ Ver en este sentido, DwORKIN, Ronald, Los derechos en Serio, Editorial Ariel S.A., Barcelona, 2005.

7 Ver sentencia del Tribunal Constitucional, de 21 de agosto de 2006.

${ }^{8}$ Ugarte Cataldo, José Luis, op. cit.
} 
que siendo una discusión acerca de la prevalencia de la libertad empresarial o de prerrogativas laborales de los trabajadores, deba ser decidida por un organismo jurisdiccional, en circunstancias que posee la fisonomía de una discusión estrictamente política, respecto de la cual ningún tribunal está legitimado a decidir ${ }^{9}$. Los conceptos constitucionales son por sí mismos incontrovertibles, ya que nadie duda que las empresas deban tener libertad, ni nadie duda al mismo tiempo que los trabajadores, parte débil de una relación jurídica, deban ser protegidos, pero esos conceptos deben ser llenados de contenido con una concepción particular de lo que ese concepto debe querer decir, y esa concepción -eminentemente política- debe ser suministrada por el órgano que posee la legitimidad democrática para hacerlo, esto es, el Parlamento. Pensar de otra manera, nos llevaría a otorgarle competencia al Tribunal para que decida por nosotros las políticas contra la delincuencia o que elija el sistema de salud que más conviene a los súbditos del reino del Tribunal Constitucional ${ }^{10}$.

El problema planteado en el párrafo anterior induce necesariamente a sostener que difícilmente podría el Tribunal Constitucional cerrar el debate sobre ninguna materia de fondo en particular, puesto que el debate es propiamente político y debe ser librado donde corresponde, tanto en el Parlamento como en la academia o los grupos intermedios directamente relacionados. El Tribunal, al no pronunciarse sobre la constitucionalidad de fondo, admite tácitamente su ilegitimidad y su incapacidad para resolver un problema tan espinudo como el concepto de empresa en la legislación laboral.

La doctrina en particular ha escrito sobre las condiciones para que una pluralidad de entes jurídicos pueda ser considerada una sola empresa para efectos laborales ${ }^{11}$. Dicha literatura trabaja sobre la jurisprudencia extranjera, cuyo desarrollo y profundidad se extrañan en la jurisprudencia chilena. Así, por ejemplo, la jurisprudencia española que, lejos de aceptar prima facie la individualidad legal determinada de las empresas, indaga sobre quién efectivamente detenta la facultad de empresa para efectos laborales. Para ello, apunta a una serie de criterios o indicios que permiten deducir cuando nos encontramos ante una unidad empresarial (no obstante constituir una pluralidad jurídica), tales como confusión de trabajadores; confusión de patrimonios sociales; dirección unitaria y apariencia externa de unidad empresarial ${ }^{12}$. Sin embargo, es más fácil para la jurisprudencia española que para los tribunales chilenos establecer dicha doctrina, pues el artículo 1.2 de la LET no hace referencia a una individualidad legal determinada, sino denomina empresario a "todas las personas, físicas o jurídicas, o comunidades de bienes que reciban la prestación de servicios...". Por lo tanto, la jurisprudencia española no sacrifica la ley, más bien la complementa y crea criterios para establecer cuando todas esas personas físicas o jurídicas constituirán una sola empresa para efectos laborales.

\footnotetext{
9 Ver ATria, Fernando, "Qué desacuerdos Valen, La Respuesta Legalista", en: Ius et Praxis, volumen 8, año 2002.

${ }^{10}$ Los ejemplos son de ATRIA, Fernando, "El Derecho y la Contingencia de lo Político", en: Revista del Centro de Estudios Públicos.

11 RoJAs Miño, Irene; AYLWIN ChIORRINI, Andrés, Los Grupos de Empresas en el Derecho Chileno del Trabajo, Editorial LexisNexis, Santiago, 2007.

12 Ver el interesante trabajo de ROJAS MiÑo, Irene; AYLWIN CHIORRINI, Andrés, "Los Grupos de Empresas y sus efectos jurídico laborales en el Derecho Comparado", en: Revista Ius et Praxis, volumen 11, año 2005, pp. 197-225.
} 
Se ha señalado que no existe necesidad de reformular el Código del Trabajo chileno, omitiendo la individualidad legal determinada del concepto de empresa, pues nuestro ordenamiento ya contempla mecanismos para hacer frente a los subterfugios que puedan menoscabar lo derechos de los trabajadores, sancionando la figura de la simulación ${ }^{13}$. No obstante, no parece ser una falacia la pretensión de modificar el artículo $3^{\circ}$ inciso 3 del Código del Trabajo, a pesar de la existencia de la figura de la simulación, pues esta requiere la prueba del fraude, prueba que en la mayoría de las ocasiones es imposible proveer. Por esa razón, la Excelentísima Corte Suprema se ve obligada a utilizar estos criterios que, al mismo tiempo que omite la individualidad legal determinada, opera como una verdadera presunción de simulación en contra de las empresas.

No parece ser controvertido que los derechos individuales y colectivos de los trabajadores deban prevalecer por sobre la complejidad del entramado jurídico de las empresas, por eso se hace imperativo la modificación del artículo $3^{\circ}$ inciso $3^{\circ}$ del Código del Trabajo. Mientras tanto, la Corte seguirá sosteniendo que quienes posean giros estrechamente vinculados o complementarios, que tengan una sola administración, funcionen en un mismo lugar y que el trabajador preste servicios indistintamente a ese grupo económico, serán considerados una sola empresa para efectos laborales, realizando una presunción que, facultativamente, la ley no le otorga y omitiendo la referencia a la "individualidad legal determinada" del Código, con todo el compromiso a la dignidad de la legislación que ello conlleva.

13 Ver la opinión de Palavecino, Claudio, "A propósito de los grupos empresariales y el concepto de empresa", en: La Semana Juridica, año $7, \mathrm{~N}^{\circ} 327,2007$. 